\title{
Comparison of Diet-Induced Thermogenesis of Foods Containing Medium- versus Long-Chain Triacylglycerols
}

\author{
Michio KASAI ${ }^{1}$, Naohisa NosaKa ${ }^{1}$, Hideaki MAKI ${ }^{1}$, Yoshie SUZUKI ${ }^{1}$, Hiroyuki TAKeUCHI ${ }^{1}$, Toshiaki Aoyama ${ }^{1}$, \\ Atsushi OHRA ${ }^{2}$, Youji HARADA ${ }^{2}$, Mitsuko OKAZAKI ${ }^{3}$ and Kazuo KONDO ${ }^{4}$ \\ ${ }^{1}$ Research Laboratory and ${ }^{2}$ Center of Food Research and Development, Nisshin Oil Mills, Ltd., \\ Shinmei-cho, Yokosuka, Kanagawa 239-0832, Japan \\ ${ }^{3}$ Kagawa Nutrition University, Chiyoda, Sakado, Saitama 350-0288, Japan \\ ${ }^{4}$ Institute of Environmental Science for Human Life, Ochanomizu University, \\ Ohtsuka, Bunkyo-ku, Tokyo 112-8610, Japan
}

(Received March 20, 2002)

\begin{abstract}
Summary The purpose of this study was to investigate the effect of 5-10 $\mathrm{g}$ of mediumchain triacylglycerols (MCT) on diet-induced thermogenesis in healthy humans. The study compared diet-induced thermogenesis after ingestion of test foods containing MCT and long-chain triacylglycerols (LCT), using a double-blind, crossover design. Eight male and eight female subjects participated in study 1 and study 2 , respectively. In both studies, the LCT was a blend of rapeseed oil and soybean oil. In study 1 , the liquid meals contained $10 \mathrm{~g}$ MCT (10M), a mixture of $5 \mathrm{~g} \mathrm{MCT} \mathrm{and} 5 \mathrm{~g} \mathrm{LCT}(5 \mathrm{M} 5 \mathrm{~L})$, and $10 \mathrm{~g} \mathrm{LCT} \mathrm{(10L).} \mathrm{In} \mathrm{study} 2$, the subjects were given a meal (sandwich and clear soup) with the mayonnaise or margarine containing $5 \mathrm{~g}$ of $\mathrm{MCT}$ or LCT. Postprandial energy expenditure was measured by indirect calorimetry before and during the $6 \mathrm{~h}$ after ingestion of the test meals. Diet-induced thermogenesis was significantly greater after $5 \mathrm{M} 5 \mathrm{~L}$ and $10 \mathrm{M}$ ingestion as compared to $10 \mathrm{~L}$ ingestion. Ingestion of the mayonnaise or margarine containing $5 \mathrm{~g} \mathrm{MCT}$ caused significantly larger diet-induced thermogenesis as compared to that of LCT. These results suggest that, in healthy humans, the intake of $5-10 \mathrm{~g}$ of MCT causes larger diet-induced thermogenesis than that of LCT, irrespective of the form of meal containing the MCT.
\end{abstract}

Key Words medium-chain triacylglycerols, healthy human, diet-induced thermogenesis, meal form

Medium-chain triacylglycerols (MCT) are found in edible oils that consist of $\mathrm{C} 8$ and $\mathrm{C} 10$ saturated fatty acids. The processes of digestion and absorption of MCT and long-chain triacylglycerols (LCT) are completely different (1). The rapid absorption of MCT makes it a valuable tool in the dietary treatment of malabsorption syndromes (2). Quite a few animal studies have provided evidence that MCT diets lead to less body fat deposition as compared to LCT diets (3-8). These results indicate that the substitution of MCT for LCT in dietary fat could reduce dietary obesity if energy intake remains constant (9).

Diet-induced thermogenesis plays an important role in the regulation of energy balance (10). It has been observed that diet-induced thermogenesis is increased after overfeeding, and is conversely decreased by starvation (11). Seaton et al. (9) and Hill et al. (12) reported that the ingestion of $400 \mathrm{kcal}(48 \mathrm{~g})$ MCT caused higher diet-induced thermogenesis than that of LCT in men. Flatt et al. (13) also observed greater diet-induced thermogenesis in healthy men after the ingestion of a mixed meal containing $40 \mathrm{~g}$ of $\mathrm{MCT}$ as compared to an isocaloric meal containing LCT. Scalfi et al. (14) found greater diet-induced thermogenesis in lean and obese

E-mail: m-kasai@nisshin.oilliogroup.com subjects after a mixed meal containing $30 \mathrm{~g}$ of MCT than that containing LCT.

Very recently, we demonstrated that the feeding of a MCT meal containing $10 \mathrm{~g}$ of MCT for $12 \mathrm{wk}$ reduced body fat in healthy subjects to a greater extent than a LCT meal (15). However, the mechanism of greater body fat loss after ingestion of the MCT meal is not clear. The meal containing $10 \mathrm{~g}$ of MCT may cause higher diet-induced thermogenesis than that containing LCT. This study, therefore, was performed to investigate the effect of 5 and $10 \mathrm{~g}$ of MCT on diet-induced thermogenesis in healthy subjects as compared to LCT.

\section{MATERIALS AND METHODS}

Subject. Sixteen healthy volunteers, who had no history of hypertension, diabetes mellitus, or hyperlipemia and were not under any medication were recruited as test subjects. Eight males (mean \pm SE: $26.8 \pm 0.7 \mathrm{y}$; BMI, $22.7 \pm 0.8 \mathrm{~kg} / \mathrm{m}^{2}$ ) and eight females $\left(28.1 \pm 1.4 \mathrm{y} ; \mathrm{BMI}, 18.8 \pm 0.4 \mathrm{~kg} / \mathrm{m}^{2}\right)$ participated in study 1 and study 2 , respectively. The studies were carried out in accordance with the Helsinki Declaration of 1964 , as revised in 2000 , and were approved by the Ethics Committee of Ochanomizu University. The study procedures were explained thoroughly to all subjects in advance, and all gave their signed informed consent be- 
fore participating.

Test oil. MCT was purchased commercially (Nisshin Oil Mills Ltd., Tokyo, Japan). Common edible oil, a blend of rapeseed oil and soybean oil (Nisshin Oil Mills), was used as the source of LCT. The fatty acid compositions were determined by a gas-liquid chromatography system (6890 series; Agilent Technologies, Palo Alto, CA, USA) with a capillary column (SP2340; Supelco, Bellefonte, PA, USA) after methylation with sodium methoxide (15). The fatty acid compositions of MCT and LCT are shown in Table 1.

Protocol. The studies were carried out in a doubleblind controlled manner with a crossover design. Throughout each study, the subjects were asked to keep their usual lifestyle, including diet and physical activity expect for the day before the diet-induced thermogenesis experiment. On that day, the subjects had dinner by $2100 \mathrm{~h}$, and fasted overnight.

Study 1: The subjects were randomly assigned to one of three experimental sessions and administered one of three liquid meals containing $10 \mathrm{~g}$ MCT (10M), a mixture of $5 \mathrm{~g} \mathrm{MCT}$ and $5 \mathrm{~g} \mathrm{LCT} \mathrm{(5M5L),} \mathrm{or} 10 \mathrm{~g} \mathrm{LCT} \mathrm{(10L).}$ The energy content of each liquid meal was 242,246 , and $250 \mathrm{kcal} / 200 \mathrm{~g}$, respectively, with proportions of protein : fat: carbohydrate (P:F : C) $21: 36: 43 \%$. The liquid meal consisted of casein, sucrose, and dextrin. The subjects ingested test meals at $1100 \mathrm{~h}$, and then rested for $6 \mathrm{~h}$. The oxygen consumption, carbon dioxide production and respiratory quotient $(\mathrm{RQ})$ were measured by an Aeromonitor AE-300S (Minato Medical Science, Osaka, Japan) before and after ingestion of the test meal for $6 \mathrm{~h}$ at $1 \mathrm{~h}$ intervals. The resting energy expenditure was calculated from oxygen consumption and carbon dioxide production using the equations of Weir (16). The Aeromonitor AE-300S consists of a microcomputer, a hot-wire flow meter, and gas analyzers containing an infrared carbon dioxide analyzer and a permanent-magnetic oxygen analyzer. Diet-induced thermogenesis was evaluated by a method reported previously (17).

Study 2: The experimental sessions were divided into two, one in which subjects were served meals with mayonnaise containing test oils, and one in which they were served meals with margarine containing test oils. The margarine and mayonnaise each contained $5 \mathrm{~g}$ of either MCT or LCT. With the exception of the test oils, the mayonnaise contained vegetables oils, vinegar, starch, mustard, and sucrose, but not eggs. The margarine contained hydrogenated oils, powdered skimmed milk, and salts. The meal was served in the form of a sandwich and clear soup. The sandwich was comprised of bread, lettuce, and tomato. The energy content of the meals containing $5 \mathrm{~g} \mathrm{LCT}$ and MCT were 253 and $249 \mathrm{kcal} /$ test meals, respectively, for the mayonnaise, and 244 and $240 \mathrm{kcal} /$ test meals, respectively, for the margarine (P : F : $\mathrm{C}=10: 40: 50 \%$ for both meal forms). One experimental session was arranged for $2 \mathrm{~d}$ in a week at 1 or $2 \mathrm{~d}$ intervals to synchronize with either a low-temperature term or a high-temperature term of the menstrual cycle $(18,19)$. The same experimental
Table 1. Fatty acid composition of test oils.

\begin{tabular}{ccc}
\hline Fatty acid & $\begin{array}{c}\text { Long-chain } \\
\text { triacylglycerols }\end{array}$ & $\begin{array}{c}\text { Medium-chain } \\
\text { triacylglycerols }\end{array}$ \\
\hline & g/100 g total fatty acids \\
$8: 0^{2}$ & $\mathrm{ND}$ & 74.4 \\
$10: 0$ & $\mathrm{ND}$ & 25.6 \\
$16: 0$ & 6.4 & $\mathrm{ND}$ \\
$16: 1$ & 0.2 & $\mathrm{ND}$ \\
$18: 0$ & 2.7 & $\mathrm{ND}$ \\
$18: 1$ & 48.6 & $\mathrm{ND}$ \\
$18: 2$ & 30.4 & $\mathrm{ND}$ \\
$18: 3$ & 10.7 & $\mathrm{ND}$ \\
$20: 0$ & 0.6 & $\mathrm{ND}$ \\
$22: 0$ & 0.4 & $\mathrm{ND}$ \\
Total & 100.0 & 100.0 \\
\hline
\end{tabular}

${ }^{1}$ Blended mixture of rapeseed and soybean oils $(7: 3)$.

${ }^{2}$ Number of carbon atoms:number of double bonds. ND, not detected.

time schedule as used in study 1 was used for study 2 . Diet-induced thermogenesis measurements were carried out under fixed conditions at a room temperature of $25-26^{\circ} \mathrm{C}$ and a room humidity of around $50-55 \%$.

Statistics. Data are presented as means \pm SE. In study 1 , results were analyzed by ANOVA, and significant differences among the liquid meals were determined by Scheffe's multiple comparison. The statistical significance of differences between the meals was tested by Student's paired $t$-test in study 2 . All analyses were performed using SPSS for Windows (Version 10.0J; SPSS Japan, Tokyo, Japan). Differences with $p<0.05$ were considered statistically significant.

\section{RESULTS}

\section{Study 1}

The resting energy expenditure before ingestion of the liquid meals was similar in the three experimental sessions: $1,690 \pm 70 \mathrm{kcal} / \mathrm{d}(\mathrm{RQ}, 0.82 \pm 0.02)$ for $10 \mathrm{M}$, $1,608 \pm 65 \mathrm{kcal} / \mathrm{d}(\mathrm{RQ}, 0.82 \pm 0.03)$ for $5 \mathrm{M} 5 \mathrm{~L}$, and $1,642 \pm 51 \mathrm{kcal} / \mathrm{d}(\mathrm{RQ}, 0.81 \pm 0.02)$ for $10 \mathrm{~L}$. Increases in oxygen consumption were greater after the ingestion of $5 \mathrm{M} 5 \mathrm{~L}$ and $10 \mathrm{M}$ than after ingestion of $10 \mathrm{~L}$ during the $6 \mathrm{~h}$ measurement period (Fig. 1). The increases in oxygen consumption were significantly greater $30 \mathrm{~min}$ after ingestion for the $5 \mathrm{M} 5 \mathrm{~L}$ and $10 \mathrm{M}$ groups as compared to the 10L group. Increases in oxygen consumption were also significantly higher at 120 and $180 \mathrm{~min}$ after ingestion for the $10 \mathrm{M}$ group as compared to the 10L group. Values of change in $\mathrm{RQ}$ were significantly smaller after the ingestion of $5 \mathrm{M} 5 \mathrm{~L}$ and $10 \mathrm{M}$ as compared to 10L (Fig. 2). Value of change in RQ was also significantly smaller at $30 \mathrm{~min}$ after ingestions for the $10 \mathrm{M}$ group as compared to the 10L group.

Diet-induced thermogenesis was significantly greater after the ingestion of $5 \mathrm{M} 5 \mathrm{~L}$ or $10 \mathrm{M}$ as compared with the ingestion of 10L; however, there was no significant difference between the 5M5L and 10M groups (Table 2 ). Rates of diet-induced thermogenesis/energy of food 


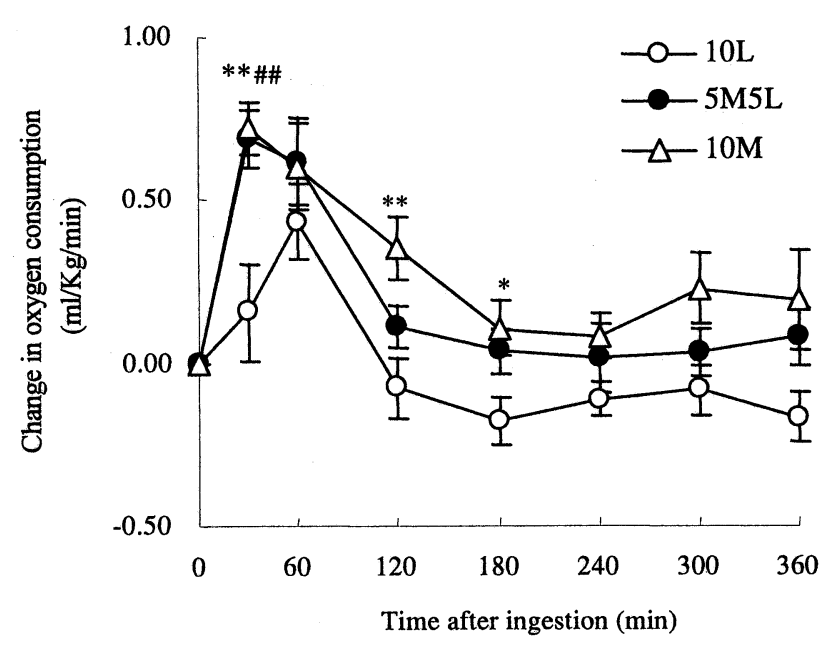

Fig. 1. Change in oxygen consumption before and after the ingestion of a liquid meal (study 1) containing $10 \mathrm{~g}$ of long-chain triacylglycerols (10L, i.e. $0 \mathrm{M})$, a mixture of $5 \mathrm{~g}$ medium-chain triacylglycerols and $5 \mathrm{~g}$ of long-chain triacylglycerols (5M5L) or $10 \mathrm{~g}$ of medium-chain triacylglycerols $(10 \mathrm{M}) .{ }^{*}$ Significant different between the $0 \mathrm{M}$ and $10 \mathrm{M}$ meals, $p<0.05$; ${ }^{* *} p<0.01$. \#\# Significantly different between the $0 \mathrm{M}$ and $5 \mathrm{M} 5 \mathrm{~L}$ diets, $p<0.01$.

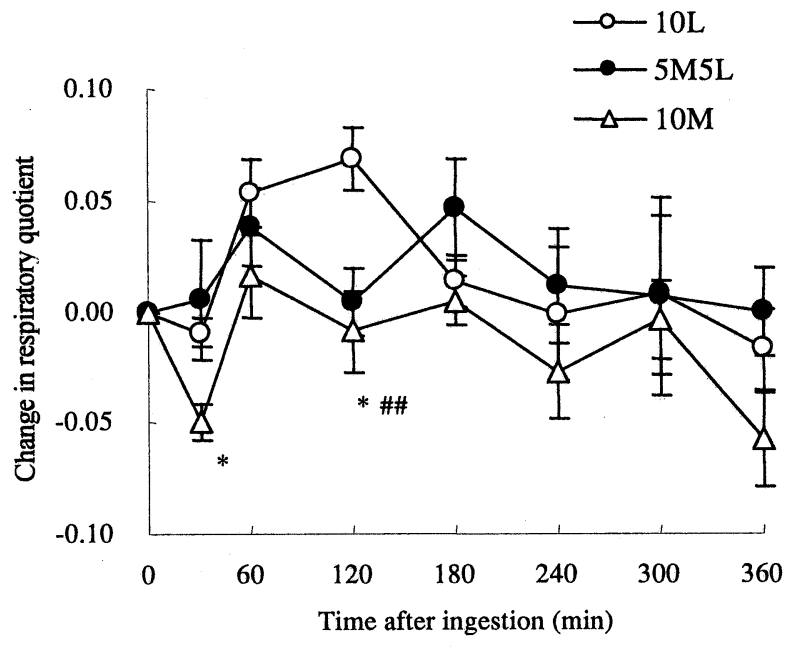

Fig. 2. Change in respiratory quotients before and after the ingestion of a liquid meal (study 1) containing $10 \mathrm{~g}$ of long-chain triacylglycerols (10L, i.e. OM), a mixture of $5 \mathrm{~g}$ medium-chain triacylglycerols and $5 \mathrm{~g}$ of long-chain triacylglycerols (5M5L) or $10 \mathrm{~g}$ of medium-chain triacylglycerols $(10 \mathrm{M}) .{ }^{*}$ Significantly different between the $0 \mathrm{M}$ and $10 \mathrm{M}$ meals, $p<0.05$. \#\# Significantly different between the $0 \mathrm{M}$ and $5 \mathrm{M} 5 \mathrm{~L}$ diets, $p<0.01$.

Table 2. Diet-induced thermogenesis during $6 \mathrm{~h}$ after ingestion of liquid meal containing 0,5 or $10 \mathrm{~g}$ of medium-chain triacylglycerols (study 1$)^{1}$

\begin{tabular}{lrrr}
\hline & & Test meal & \\
\cline { 2 - 4 } & $10 \mathrm{~L}^{2}$ & $5{\mathrm{M} 5 \mathrm{~L}^{2}}^{2}$ & $10 \mathrm{M}^{2}$ \\
\hline Diet-induced thermogenesis (cal/kg) & $172.6 \pm 36.0$ & $387.1 \pm 102.0^{* *}$ & $412.5 \pm 112.6^{* *}$ \\
Rate of diet-induced thermogenesis $(\%)^{3}$ & $4.81 \pm 1.05$ & $10.30 \pm 2.38^{* *}$ & $11.53 \pm 3.15^{* *}$ \\
\hline
\end{tabular}

\footnotetext{
${ }^{1}$ Mean \pm SE; $n=8$.

${ }^{2}$ Liquid diet containing $10 \mathrm{~g}$ long-chain triacylglycerols (10L), mixture of $5 \mathrm{~g}$ medium-chain triacylglycerols and $5 \mathrm{~g}$ longchain triacylglycerols (5M5L) or $10 \mathrm{~g}$ medium-chain triacylglycerols (10M).

${ }^{3}$ Rate of diet-induced thermogenesis was calculated as diet-induced thermogenesis/energy of food consumption.

** Significantly different from the 10L diet, $p<0.01$.
}

Table 3. Diet-induced thermogenesis during $6 \mathrm{~h}$ after ingestion of meal (sandwich and clear soup) with mayonnaise and margarine containing $5 \mathrm{~g}$ of long-chain triacylglycerols or medium-chain triacylglycerols (study 2 ). ${ }^{1}$

\begin{tabular}{lccccc}
\hline \multirow{2}{*}{ Test oil } & \multicolumn{2}{c}{ Mayonnaise $(n=7)^{2}$} & & \multicolumn{2}{c}{ Margarine $(n=8)$} \\
\cline { 2 - 5 } \cline { 5 - 6 } & $5 \mathrm{~g} \mathrm{LCT}$ & $5 \mathrm{~g} \mathrm{MCT}$ & & $5 \mathrm{~g} \mathrm{LCT}$ & $5 \mathrm{~g} \mathrm{MCT}$ \\
\hline Diet-induced thermogenesis (cal/kg) & $220.7 \pm 71.3$ & $399.0 \pm 65.4^{*}$ & & $273.8 \pm 81.9$ & $574.1 \pm 156.7^{*}$ \\
Rate of diet-induced thermogenesis $(\%)^{3}$ & $4.62 \pm 1.49$ & $8.05 \pm 1.33^{*}$ & & $5.75 \pm 1.82$ & $12.12 \pm 3.54^{*}$ \\
\hline
\end{tabular}

\footnotetext{
${ }^{1}$ Mean \pm SE.

${ }^{2}$ One female subject could not participate in a experiment with mayonnaise owing to personal matters.

${ }^{3}$ Rate of diet-induced thermogenesis was calculated as diet-induced thermogenesis/energy of food consumption.

* Significantly different from the meal containing $5 \mathrm{~g} \mathrm{LCT}, p<0.05$.
}

consumption were also significantly greater after the ingestion of $5 \mathrm{M} 5 \mathrm{~L}$ or $10 \mathrm{M}$ ingestion as compared to $10 \mathrm{~L}$.

Study 2

Due to personal circumstances, one of the female subjects was unable to participate in the experiment that included the consumption of mayonnaise. The resting energy expenditure before ingestion of the meals containing 0 or $5 \mathrm{~g}$ of $\mathrm{MCT}$ were the same in the four experimental sessions: $1,211 \pm 35 \mathrm{kcal} / \mathrm{d}$ (RQ, 
$0.84 \pm 0.04)$ and $1,182 \pm 53 \mathrm{kcal} / \mathrm{d}(\mathrm{RQ}, 0.83 \pm 0.03)$, respectively, for the mayonnaise, and $1,201 \pm 76 \mathrm{kcal} / \mathrm{d}$ $(\mathrm{RQ}, 0.81 \pm 0.05)$ and $1,137 \pm 71 \mathrm{kcal} / \mathrm{d}(\mathrm{RQ}, 0.82 \pm$ $0.03)$, respectively, for the margarine. Both of the meals with the mayonnaise and margarine containing $5 \mathrm{~g}$ of MCT resulted in significantly greater diet-induced thermogenesis compared with that of LCT (Table 3). In both meals of mayonnaise and margarine, the rates for dietinduced thermogenesis/energy of food consumption were significantly higher after the ingestion of $5 \mathrm{~g} \mathrm{MCT}$ as compared to LCT ingestion. The rates of diet-induced thermogenesis energy of food consumption were similar after ingestion of the two types of meals.

\section{DISCUSSION}

A greater thermogenic effect of MCT than LCT has been demonstrated in humans after the ingestion of a considerable amount (30 g or more) $(8,12-14)$. However, the effect of 5-10 g MCT, which could be easily replaced with cooking oil on diet-induced thermogenesis is not known well in healthy humans. In study 1 , diet-induced thermogenesis after the ingestion of a liquid meal containing 0,5 or $10 \mathrm{~g}$ of MCT was measured in healthy men. Diet-induced thermogenesis was significantly greater after the ingestion of $5 \mathrm{M} 5 \mathrm{~L}$ or $10 \mathrm{M}$ as compared to 10L. Ingestion of $5 \mathrm{M} 5 \mathrm{~L}$ or $10 \mathrm{M}$ resulted in approximately twice as much in diet-induced thermogenesis as the ingestion of 10L. These results suggest that an intake of MCT at a volume of 5-10 g causes larger diet-induced thermogenesis than the intake of LCT in healthy humans. Dulloo et al. (20) observed greater $24 \mathrm{~h}$ energy expenditure in subjects that ingested a typical Western breakfast, lunch and dinner containing 5 $\mathrm{g}$ of MCT, respectively, as compared to an isocaloric meal containing LCT. Our results in this study are compatible to the findings reported by Dulloo et al.

Form and palatability of meal influence diet-induced thermogenesis. Diet-induced thermogenesis was greater after the ingestion of a normal meal as compared to the ingestion of a finely ground meal (21). Therefore, in study 2 , we compared diet-induced thermogenesis after the ingestion of a meal (sandwich and clear soup) containing $5 \mathrm{~g}$ of MCT or LCT. In both meals, with mayonnaise and margarine, diet-induced thermogenesis was significantly greater after the ingestion of MCT as compared to LCT ingestion. Ingestion of the meals with mayonnaise and margarine containing MCT resulted in approximately double the diet-induced thermogenesis as compared to the ingestion of the meals containing only LCT. The results of this study strongly suggest that an intake of $5 \mathrm{~g}$ MCT causes larger diet-induced thermogenesis as compared to the intake of LCT in healthy humans. White et al. (22) reported that diet-induced thermogenesis was greater after the ingestion of a MCTenriched diet $(7.1 \pm 0.1 \mathrm{~g} / \mathrm{d})$ for $14 \mathrm{~d}$ as compared to the ingestion of a LCT diet, but not significantly. In their study, butter and coconut oil, which contain mainly lauric and myristic acids rather than caprylic and capric acids, were the fats used to increase the proportion of MCT in the diet. The MCT used in our experi- ment, however, contained only caprylic and capric acids (Table 1 ).

Long-chain fatty acids absorbed at the small intestine flow into the venous system via lymphatic vessels and are transported to peripheral tissues such as adipose tissue and muscle. Most medium-chain fatty acids, however, transfer to the liver via the portal vein (2). Medium-chain fatty acids can be transported through the mitochondrial membrane without binding to carnitine and easily move into the mitochondria, where $\beta$-oxidation occurs (1). Because liver contributes about $30 \%$ to the basal metabolic rate (23), direct transportation of MCT from the small intestine to the liver may be related to the larger diet-induced thermogenesis (9, 24 ). On the other hand, Dulloo et al. (20) observed that $24 \mathrm{~h}$ urinary noradrenaline, an index of sympathetic activity, was increased after the ingestion of MCT, and proposed that the higher energy expenditure resulting from the ingestion of MCT is mediated though activation of the sympathetic nervous system. A detailed study is required to clarify the mechanism.

In conclusion, our results suggest that the intake of 5-10 $\mathrm{g}$ of MCT by healthy humans gives larger diet-induced thermogenesis than that of LCT, irrespective of the form of meal containing the MCT. These data suggest the possibility that the substitution of MCT for cooking oil is useful to control body weight and fat in healthy subjects.

\section{Acknowledgments}

The authors wish to acknowledge the technical guidance and advice given by F. Yamaki MD, S. Masuda, H. Tsuji, M. Nakamura, H. Negishi, M. Oozeki, and S. Nakajima. The authors also wish to thank A. Nagatoishi, C. Itou, K. Okamoto, K. Muroga, Y. Saitou, and $\mathrm{H}$. Haruna for production of test meals.

\section{REFERENCES}

1) Papamandjaris AA, MacDougall DE, Jones PJH. 1998. Medium chain fatty acid metabolism and energy expenditure: Obesity treatment implications. Life Sci 62: 1203-1215.

2) Bach AC, Babayan VK. 1982. Medium-chain triglycerides: an update. Am J Clin Nutr 36: 950-962.

3) Geliebter A, Torbay N, Bracco EF, Hashim SA, Van Itallie TB. 1983. Overfeeding with medium-chain triglyceride diet results in diminished deposition of fat. Am J Clin Nutr 37: 1-4.

4) Lavau MM, Hashim SA. 1978. Effect of medium chain triglyceride on lipogenesis and body fat in the rat. J Nutr 108: 613-620.

5) Schemmel R. 1976. Physiological consideration of lipid storage and utilization. Am Zool 16: 661-670.

6) Travis D, Minenna A, Frier H. 1979. Effect of medium chain triglyceride on energy metabolism and body composition in the rat. Fed Proc 38: 561.

7) Baba N, Bracco EF, Hashim SA. 1982. Enhanced thermogenesis and diminished deposition of fat in response to overfeeding with diet containing medium chain triglyceride. Am J Clin Nutr 35: 678-682.

8) Bray GA, Lee M, Bray TL. 1980. Weight gain of rats fed medium-chain triglycerides is less than rats fed long- 
chain triglycerides. Int J Obesity 4: 27-32.

9) Seaton TB, Welle SL, Warenko MK, Campbell RG. 1986. Thermic effect of medium-chain and long-chain triglycerides in man. Am J Clin Nutr 44: 630-634.

10) Himms-Hagen J. 1984. Thermogenesis in brown adipose tissue as an energy buffer. $N$ Engl J Med 311 1549-1558.

11) Bray GA. 1983. The energetics of obesity. Med Sci Sports Exerc 15: 32-40.

12) Hill JO, Peters JC, Yang D, Sharp T, Kaler M, Abumrad NN, Greene HL. 1989. Thermogenesis in humans during overfeeding with medium-chain triglycerides. Metabolism 38: 641-648.

13) Flatt JP, Ravussin E, Acheson KJ, Jequier E. 1985. Effect of dietary fat on postprandial substrate oxidation and carbohydrate and fat balances. J Clin Invest 76: 1019-1024.

14) Scalfi L, Coltorti A, Contaldo F. 1991. Postprandial thermogenesis in lean and obese subjects after meals supplemented with medium-chain and long-chain triglycerides. Am J Clin Nutr 53: 1130-1133.

15) Tsuji H, Kasai M, Takeuchi H, Nakamura M, Okazaki M, Kondo K. 2001. Dietary medium-chain triacylglycerols suppress accumulation of body fat in a double-blind, controlled trial in healthy men and women. J Nutr 131: 2853-2859.

16) Weir JB. 1949. New methods for calculating metabolic rate with special reference to protein metabolism. $J$ Physiol 109: 1-9.

17) Matthews JNS, Altman DG, Campbell MJ, Royston P.
1990. Analysis of serial measurements in medical research. Br Med J 300: 230-235.

18) Ferraro R, Lillioja S, Fontvieille AM, Rising R, Bogardus C, Ravussin E. 1992. Lower sedentary metabolic rate in women compared with men. J Clin Invest 90: 780-784.

19) Tai MM, Castillo PF, Pi-Sunyer FX. 1997. Thermic effect of food during each phase of the menstrual cycle. Am J Clin Nutr 66: 1110-1115.

20) Dulloo AG, Fathi M, Mensi N, Girardier L. 1996. Twenty-four-hour energy expenditure and urinary catecholamines of humans consuming low-to-moderate amount of medium-chain triglycerides: a dose-response study in a human respiratory chamber. Eur J Clin Nutr 50: $152-158$.

21) Leblanc J, Brondel L. 1985. Role of palatability on mealinduced thermogenesis in human subjects. Am J Physiol 248: E333-E336.

22) White MD, Papamandjaris AA, Jones PJH. 1998. Enhanced postprandial energy expenditure with medium-chain fatty acid feeding is attenuated after $14 \mathrm{~d}$ in premenopausal women. Am J Clin Nutr 69: 883-889.

23) Danforth E. 1992. Regulation of energy expenditure. In: Obesity: Basic Concepts and Clinical Aspects (Belfiore F, Jeanrenaud B, Papalia D, eds), Vol 11, p 61-77. Kargar, Basel, Switzerland.

24) Berry MN, Clark DG, Grivell AR, Wallace PG. 1985. The contribution of hepatic metabolism to diet-induced thermogenesis. Metabolism 24: 141-147. 